Int. J. Electrochem. Sci., 15 (2020) 3347 - 3364

\title{
Novel Potentiometric Sensors Based on B-cyclodextrin and Dibenzo 18-crown-6 Ionophores/Mesoporous Silica Nanoparticles for Clidinium Determination
}

\author{
Sahar Mahmoud Mostafa ${ }^{1, *}$, Ahmed Ali Farghali ${ }^{2}$ and Mohamed Magdy Khalil ${ }^{1}$ \\ ${ }^{1}$ Chemistry Department, Faculty of Science, Beni-Suef University, Beni-Suef, Egypt. \\ ${ }^{2}$ Materials Science and Nanotechnology Department, Faculty of Postgraduate Studies for Advanced \\ Sciences, Beni-Suef University, Beni-Suef, Egypt. \\ *E-mail: dr_saharmahmoud888@yahoo.com
}

doi: $10.20964 / 2020.04 .48$

Received: 2 December 2019 / Accepted: 26 January 2020 / Published: 10 March 2020

For the first time, two novel potentiometric sensors based on B-cyclodextrin/mesoporous silica nanoparticles ( $\beta$-CD/MSNs-CPS, sensor I) and dibenzo 18-crown-6/mesoporous silica nanoparticles (DB18C6/MSNs-CPS, sensor II) were described for potentiometric determination of clidinium bromide (CDB). The sensor matrix optimization was focused on the nature and content of the sensing element, plasticizer, anionic additive and nanomaterials. The fabricated sensors showed linear, stable and Nernstian slopes of $59.9 \pm 0.5$ and $56.6 \pm 0.3 \mathrm{mV} \mathrm{decade}^{-1}$ and detection limits of $6.8 \times 10^{-8}$ and $9.0 \mathrm{x}$ $10^{-8} \mathrm{~mol} \mathrm{~L}^{-1}$ for sensors I and II, respectively. The morphology and properties of sensors surface were characterized by scanning electron microscopy (SEM), transmission electron microscopy (TEM) and electrochemical impedance spectroscopy (EIS), respectively. The sensors were found to be accurate and usable within wide $\mathrm{pH}$ range (4.0-11.5) in short response times (4 and $8 \mathrm{~s}$ ). The thermal stability coefficients of the investigated sensors were 0.00041 and $0.00032 \mathrm{~V}^{\circ} \mathrm{C}^{-1}$. The sensors showed adequate selectivity against some inorganic cations and were felicitously implemented for CDB determination in pure solutions, pharmaceutical preparation, biological fluids and surface water samples.

Keywords: Carbon paste sensors; Clidinium bromide; Mesoporous silica nanoparticles; Pharmaceutical analysis; Surface water

\section{$\underline{\text { FULL TEXT }}$}

(C) 2020 The Authors. Published by ESG (www.electrochemsci.org). This article is an open access article distributed under the terms and conditions of the Creative Commons Attribution license (http://creativecommons.org/licenses/by/4.0/). 